Revista Destaques Acadêmicos, Lajeado, v. 11, n. 2, 2019. ISSN 2176-3070

DOI: http://dx.doi.org/10.22410/issn.2176-3070.v11i2a2019.2095

http://www.univates.br/revistas

\title{
SEU MESTRE MANDOU! PERCEPÇÕES DE UM PSICÓLOGO NO AMBIENTE ESCOLAR
}

\author{
Breno Freitas Burgardt ${ }^{1}$, Gracielle Almeida de Aguiar ${ }^{2}$
}

Resumo: O presente texto constitui-se em um relato de experiência de um estagiário do curso de psicologia em um contexto de escola e educação. Os seguintes relatos de estágio possuem o objetivo de demonstrar a rotina e a experiência da psicologia na escola. A experiência dentro da instituição escolar é permeada por um olhar de viés psicanalítico frente às demandas e situações que se apresentaram na instituição, tendo como fonte bibliográfica: artigos científicos e livros. O seguinte relato mostra uma visão de escola muito além de dificuldades e obstáculos e sim, de nossos próprios sintomas e reatualizações de nossas próprias experiências escolares.

Palavras-chave: Psicologia escolar. Psicólogo escolar. Educação.

\section{INTRODUÇÃO}

A educação aqui representada pela escola constitui-se como um meio essencial na díade ensino-aprendizagem e também do processo de socialização das crianças e adolescentes. Dentro dessa estrutura intensa e cheia de contradições é que se faz a rotina de uma escola. As seguintes palavras vão de encontro à necessária e questionadora presença do psicólogo como um membro atuante e também mutável em um contexto escolar. O presente relato surge como uma demanda acadêmica do curso de Psicologia da Universidade Luterana do Brasil (ULBRA) com o intuito de compartilhar experiências vivenciadas a partir da realização de estágio acadêmico, bem como de ambientar e estruturar uma convivência e experiência na escola que acaba se estendendo em uma importante narrativa em que são trazidos aspectos ímpares de uma instituição de ensino que em muitos momentos aparente ter um zeitgeist próprio.

1 Psicólogo. Especialista em Gestão de Organização Pública em Saúde pela Universidade Federal de Santa Maria-RS.

2 Psicóloga. Mestranda do programa de pós-graduação em Psicologia pela Universidade Federal de Santa Maria-RS. 


\section{Histórico da Instituição}

O Instituto Estadual de Educação Olavo Bilac (IEEOB) descende de uma cultura de criação de institutos estaduais de educação derivando da implantação de uma política de democratização do ensino. Segundo Pacheco (2012), a educação no início do século XX tinha o traço de um "monopólio" dos ricos que estabeleciam a crença de que a educação correspondia a um conceito de status social, tendo a possibilidade de educação somente aqueles que derivavam de elevada "casta" financeira. Durante muito tempo a classe mais pobre conviveu com esta questão até nos primeiros anos do século XX, surgirem os institutos estaduais que visavam à democratização da educação do ensino.

Localizado em Santa Maria, no Rio Grande do Sul, tal instituto surge como um colégio distrital em 1901 em um casarão alugado pela prefeitura. Em 1936 pelo tamanho e condições do casarão, o governo estadual manda construir no local um pavimento com três edifícios e com salas para suprir as demandas de colégio, sendo reinaugurado em 1938. Entre 1910 e 1979 a instituição teve diversas denominações até que em 2000 a escola passa a ser denominada oficialmente, Instituto Estadual de Educação Olavo Bilac, nomenclatura utilizada até os dias de hoje. Atualmente a instituição atende a 1765 alunos, distribuídos na educação infantil e especial, anos iniciais, curso normal, ensino médio e Ensino de Jovens e Adultos (EJA).

\section{Costurando retalhos}

O semestre se fez de grandes experiências que contribuíram de maneira significativa para algumas realizações que se deram na escola. Sendo o semestre a continuação do período anterior do estágio específico, se faz essencial uma união de alguns elementos que vinham acontecendo no último semestre e que muitas vezes modificaram-se ou se "costuraram" em outras frentes na instituição.

Em relação aos trabalhos que vinham se constituindo até o período passado, puderam-se notar algumas transformações na realidade da instituição escolar. Tais modificações partem de algumas questões que dizem da relação dos professores e funcionários com os estagiários de psicologia e com algumas intervenções realizadas na instituição. $O$ trabalho que foi realizado até então se construiu com conquistas de espaço que se deram através da escuta dos professores, funcionários e alunos. $\mathrm{O}$ que se fez foi assumir o compromisso, respeito e abertura a singularidade de cada um na escola, respondendo a uma ética que diz do inconsciente e não de um discurso moral. A ética do analista constitui-se em sustentar a emergência do sujeito do inconsciente para o sujeito, mesmo o sujeito muitas vezes recusando o seu reconhecimento no discurso, nos lapsos ou no gozo do sintoma através da descarga na pulsão de morte (DASSOLER \& PALMA, 2012, p.98). Aqui se demonstra a importância 
e as possibilidades que se costuram junto àqueles que se dispõe a ouvir o que muitas vezes, quase todos tapam os ouvidos.

O que fica explícito no decorrer de todo o estágio é a importância da continuidade de um trabalho que diga da possibilidade da construção de um discurso distinto, do que se apresenta inicialmente ao estágio. A possibilidade de construção de algo se faz no ato juntamente com o outro. De tal forma a construção se faz em uma presença, que diz de uma parceria que proporciona novas formas de criar e se reinventar. Faço a analogia aos retalhos, pois, são eles que se apresentam na rotina da escola com todas as suas tonalidades e formatos. Os retalhos em si em uma colcha não se costuram em uma solidão, da mesma forma que um retalho não faz uma colcha.

\section{Garatujas}

Segundo o dicionário Michaelis da língua portuguesa a expressão garatuja se estabelece como: sf (ital grattugia) 1- Escrita com letras disformes, malfeitas e pouco inteligíveis (muito usado no plural); garafunhas, garafunhos, garavunha, gatafunhos e gregotins. 2- Esgar, momice, trejeito. 3- Tolice. Tal expressão se faz essencial em nosso trajeto, pois diz muito de todo o processo de estágio na escola. As garatujas foram companheiras inseparáveis em todas as atividades que foram propostas na instituição. Principalmente no trabalho inicial onde as barreiras se firmaram e muitas vezes ainda se firmam, são as garatujas da instituição que se apresentaram antes mesmo de termos um contato qualquer com a possibilidade da lógica escolar.

O garatujar inicial tomou por muito tempo o trabalho dos acadêmicos na instituição, seja qual fosse à atividade proposta. As atividades que se desenvolveram seguiram o acompanhamento dessas garatujas que a escola fornecia até transformar-se em letra. Segundo Levin (1998, p.122) O garatujar, o desenhar não figuradamente, sobre qualquer superfície adquire um papel estruturante no caminho da criança, cujo alvo final será a escritura alfabética. Acompanhar esse processo de criação para a transformação em letra foi um passo muito importante até que se possa ter uma aquisição de uma escrita simbólica que diga da realidade da escola.

Ainda de acordo com Levin (1998, p. 120-121) esse ato singular de escrita não figurativa delimita no mesmo momento em que inscreve uma presença no ato do sujeito. Esses traços e essas marcas não fazem signo, e sim, enunciam a existência do sujeito na própria escrita da letra. Foi a possibilidade de proporcionar abertura a tais marcações que faz com que se consiga um movimento discursivo na escola, onde não somente exista a queixa como prioridade, e também, venha à tona o desejo daqueles que fazem da escola uma oportunidade para fazer diferente. 


\section{Era Uma Vez...}

O projeto que foi proposto inicialmente dizia de um grupo com contadores de histórias. De tal forma estabeleceria a possibilidade das crianças da escola contarem suas histórias através dos grandes clássicos infantis dos irmãos Grimm. As crianças que participariam do grupo seriam aquelas envolvidas em queixas das professoras da escola. As crianças ditas "problemáticas" pelas professoras e que acompanhavam, na maior parte das vezes, um rótulo. A opção pelas histórias dos irmãos Grimm recaí em relação à crueza e a realidade mais primitiva que rege as construções dessas histórias. Antes de prosseguirmos, coloco a importância das histórias infantis como ferramenta na construção subjetiva da criança. Muito mais do que narrar histórias com temáticas variadas e entrelaçadas em um enredo próprio, às histórias infantis fazem da realidade infantil uma possibilidade. Contendo nas histórias a possibilidade para a criança brincar com a realidade, e muito mais, brincar com a sua realidade fazendo-se protagonista de sua própria história. Lendo e contemplando o livro infantil a criança se vê fantasiada e mascarada com as cores advindas de tal obra, preparando-se para um baile de máscaras onde as palavras se lançam e revolteiam-se confusamente como a uma brincadeira com sonoros flocos de neve (BENJAMIN, 2002, p.70).

Segundo Ramalho (2006, p.25) o sujeito surge e passa a obter um lugar no mundo através de narrativas que estruturam sua vida. A narrativa proporciona a experiência do eu, possibilitando uma consistência imaginária ao eu. Permite ao sujeito responder ao questionamento quem sou eu, derivado através de uma ficção, isto é, de uma narrativa que constrói sua história. A proposta eram embarcar nas histórias infantis na tentativa de que se pudesse reinventar através das histórias infantis.

Em meio às atividades do grupo com as crianças um novo formato foi se construindo, aos poucos as histórias infantis foram ficando de lado dando espaço a brincadeiras e correrias, a história começou a ser contada de um modo diferente por elas mesmas. As brincadeiras como os jogos de futebol deram outro semblante aos encontros nas quartas-feiras de manhã. Os gritos de gols frenéticos, as comemorações efusivas e as discussões acaloradas por lances duvidosos tornaram-se o tempero dos encontros do grupo. Em meio ao ritmo de copa do mundo até um hall com os superstars da copa do mundo foi montado nas paredes da sala de atividades, a "brizoleta" como chamam os professores.

A questão que se constrói em relação à construção dos grupos na escola reflete a exigência e dedicação que se faz a quem se dispõe a trabalhar com grupos e com crianças mais exatamente. No início do semestre me dispus a criar um grupo com contadores de histórias, no primeiro encontro com as crianças a ideia do grupo como tinha planejado se desfaz quase que completamente. De certa forma foi aí que se fez o grupo, em um contato com o desejo daqueles que partilhavam de algo comum. A construção que se faz partindo do desejo, se faz na percepção de que os membros do grupo partilhavam de desejos como: 
o futebol e vôlei. É no ligar-se ao desejo que se pode compartilhar de uma atmosfera de criação, onde as histórias são contadas e recontadas a cada lance de dados. O grupo com histórias infantis fica em stand by para uma nova cena que se constitui onde histórias são contadas através das brincadeiras e jogos. Tais histórias surgem a partir da narrativa dos alunos, onde as criam utilizando como pano de fundo suas próprias vivências cotidianas. Como aponta Rickes \& Gleich (2009, p.113) a oficina requer um processo de constante reinvenção para que possa se sustentar, permitindo que seus movimentos encontrem eco e que as ações que acontecem nela possam se refletir.

\section{O Maior Espetáculo da Terra}

O grupo a partir dos primeiros encontros toma outras proporções, inesperadas no momento e de grande importância para as atividades que se desenvolveriam após alguns novos encontros. Em meio a um dos encontros iniciais com o grupo nos deparamos, com alguns questionamentos das crianças que nos fizeram pensar melhor, como trabalharíamos no grupo. Alguns balbucios "rolavam" entre as crianças, até entrar em questão o que cada um gostava de fazer. Atividades dos mais variados temas se faziam presente, até que Cássio (nome fictício de um dos componentes do grupo) interpela a todos, dizendo: "Eu não gosto de nada o que vocês falaram... Eu gosto é de futebol", imediatamente outro componente do grupo diz que também gosta de futebol propondo a possibilidade de jogarmos futebol. Cássio, um grande admirador do jogador português Cristiano Ronaldo, faz um "furo" em relação ao que se tinha, abrindo espaço para darmos outros rumos para o grupo. Novos ares começaram a soprar através das dependências da escola e dos desejos dos componentes.

As atividades posteriores giraram através de jogos no pátio da escola. $\mathrm{O}$ número de componentes do grupo foi de 07 crianças entre 9 e 11 anos, sendo 6 meninos e uma menina. Apesar da predominância de meninos, o futebol agradou também Lili (nome fictício). A intenção era fazer com que os papéis e a posição de saber pudesse circular entre ambos os componentes do grupo. Lili se manteve compenetrada no futebol, muitas vezes sendo a juíza do jogo, torcedora, goleira e também muitas vezes artilheira da partida. As partidas se constituíram muitas vezes por "pelejas" regadas por discussões e brigas acirradas que se apaziguavam ao meio de uma volta rápida de jogo, o que importa é que a bola role. Em outros encontros, o futebol foi deixado de lado e substituído pelo jogo de três cortes, onde a rapidez e a pontaria de cada um dos componentes exigem bastante. $\mathrm{O}$ brincar se vê aliada a uma arte em que todos podem estar autorizados a criar. Segundo Rivera (2002, p.68) a arte através da psicanálise ligada à questão do desejo convida um colocar-se à deriva e ao movimento, posto que o desejo não se nomeia ou localiza e sim, se esquiva e ressurge em outra parte. 
O grupo se constituiu com as crianças que eram indicadas pelos professores e pais dos mesmos. Quase sempre os professores chegavam aos estagiários com perguntas que falavam de uma tentativa de ajuda com seus próprios alunos. "Tu és da psicologia... Eu tenho um aluno... (rótulo ou alguma reclamação). O grupo se formou com os "impossíveis", os que "não aprendem" ou "disléxico, hiperativo, entre outros". Essa foi uma marca que se vê constante no discurso escolar. Diferentemente do que se diz, o grupo é formado com crianças que no seu discurso buscam se reinventarem a cada encontro. Resgato Jacques Lacan, em seu Seminário IV - A relação de objeto (LACAN, 1995/195657, p.381), afirma que:

Parece-me que há um mínimo exigível na formulação analítica, que é perceber o seguinte. Certamente, o homem lida com seus instintos - instintos nos quais acredito, digam o que disserem, que se inclua o instinto de morte. Mas o que foi nos dito pela análise nos permite, mesmo assim, prever que as coisas não possam se resumir a uma fórmula tão simples, tão simplória quanto aquela que no entanto vemos tão comumente os analistas adotarem, a saber que, em suma, tudo se resolve quando as relações de sujeito com seus semelhantes são, como se diz, relações de pessoa a pessoa e não relações com um objeto.

\section{Seu Mestre Mandou!}

Em todo trabalho realizado na escola pode-se notar a dominância de um discurso predominantemente cientificista em relação aos alunos da escola. A busca de um saber que diga da criança se expressa em todos os momentos que a angústia de não ter uma resposta concreta e certa se impõe. Uma prática que se fez inicial na instituição foi de receber tanto das professoras quanto das coordenadoras pedagógicas, o nome das crianças juntamente com um entre aspas nos quais se cola um diagnóstico psiquiátrico de determinada criança. A cultura diagnóstica emerge como uma tábua de salvação em relação àquilo que não se sabe. Em muitos casos, a criança não passou por um processo de escuta sequer que diga um pouco da relação dessa criança, chegando por parte da observação de comportamentos da criança a uma conclusão integrativa àquela criança por parte de alguns professores e coordenadores. De acordo com Vorcaro (2011, p.219) reduzir a criança a um saber médico é condená-la a uma perda cultural originária. Destacando um nome que a coloca no anonimato e a joga em outra família de genealogia médica.

Além disso, alguns fatores socioeconômicos e de cultura familiar trazem fortes cargas significantes em relação às crianças. A ordem familiar, juntamente com as histórias das famílias são tomadas como uma verdade que encaminha a criança para um destino certo, não cabendo em muitas situações o questionamento sobre a mesma. Tais afirmações encerram a criança 
quanto a um sujeito biológico, familiar ou escolar premeditado e concluído. A condenação a repetir o que diz a brincadeira infantil: "seu mestre mandou", nos faz pensar o que se pode ou não fazer ou repetir referente à criança.

Um trabalho com professores e demais funcionários da escola é de fundamental importância para dar um prosseguimento ao trabalho na instituição escolar. Frente a muitas resistências e um trabalho ainda em pequenos passos, não se fez possível uma intervenção mais significativas junto aos professores e funcionários.

\section{CONSIDERAÇÕES FINAIS}

Trabalhar na escola requer confrontar-nos com aquilo que também diz de todo o nosso processo escolar. É ver-se com a impossibilidade e o fracasso que são necessários para a conquista de novos ares. A escola insere as marcas necessárias a uma constituição de laços sociais mais amplos. São tantas e inumeráveis as posições que tomam a escola como essencial ao desenvolvimento, mas me proponho a ousar em dizer que a escola se estabelece em uma reatualização constante de um desejo que diz da constituição de sujeito.

Quem mais sabe sobre a escola? Muitos diriam os especialistas, os coordenadores ou os gestores. Ao passo que o trabalho na escola vai se estabelecendo, testemunho uma posição que diz que as peças chaves na escola são os professores. É através deles que o desejo se reatualiza e marca a criança para que possa ir além daquilo que já se sabe. É com o professor que a paixão pelo desconhecido se ressignifica a todo o momento. O papel do psicólogo na escola se encaixa em uma ferramenta que possibilita que a chama do desejo se faça presente novamente nesse professor, que faz com que o saber siga adiante.

Em meio a retalhos, garatujas, histórias e brincadeiras o trabalho em que nos abraçamos recaí sobre uma impossibilidade que diga um pouco do nosso próprio sintoma. Sendo assim, pode-se observar que tais vivências junto à instituição de ensino produziu a oportunidade de questionar e perceber que a escola não era só isso que diziam (dificuldades e obstáculos), mas também, algo mais de um dizer implícito. Como reflexo social, a escola expõe aquilo que diz de nós mesmos. Despertando paixões ou desprezo, a escola refaz o seu percurso novamente todos os anos, com suas forças ela teima em continuar mesmo com as adversidades. Como no brincar infantil a escola escancara a sua verdade, apresentando a beleza que se dispõe no que é mais instintual ao ser humano: a raiva, a violência, a alegria e a criação, exigindo apenas a disponibilidade daqueles que se propõem a trabalhar com seus discursos e desejos.

\section{REFERÊNCIAS}

BENJAMIN, W. Reflexões sobre a criança, o brinquedo e a educação. São Paulo: Editora 34, 2002. 
DASSOLER, V. A.; Palma, C. M. de S. A dimensão da ética nas intervenções do analista frente às demandas institucionais dos CAPS. Revista Latinoamericana de psicopatologia. São Paulo, v. 15, n. 1, Mar. 2012. Disponível em: <http:/ / www.scielo. br/scielo.php?script=sci_arttext\&pid=S1415-47142012000100008\&lng=en\&nrm=iso $>$.

MICHAELIS. Moderno Dicionário da Língua Portuguesa. Disponível em:<http:/ / michaelis.uol.com.br/moderno/portugues/index.php?lingua=portuguesportugues\&palavra $=$ garatuja $>$.

LACAN, J. O Seminário - livro 4 - A Relação de objeto. Rio de Janeiro: Jorge Zahar Ed., 1995

LEVIN, E. A garatuja como vestígios da letra. Estilos da Clínica - Revista sobre a infância com problemas. São Paulo: IP-USP, n. 4. 1998(I), p. 120 - 123. Disponível em: http://www.revistas.usp.br/estic/article/view/60758>

OSTERMANN, R. C. Educação e cidadania. In: JERUSALINSKY, Alfredo; MELMAN, Charles, Et al. Educa-se uma criança? 2 ed. Porto Alegre: Artes e Ofícios, 2010, p. 255265.

PACHECO, L. S. Instituto estadual de educação Olavo Bilac - 110 anos: preservação e historicidade. Dissertação mestrado - Universidade Federal de Santa Maria, Centro de Ciências Sociais e Humanas, Programa de Pós-Graduação Profissionalizante e Patrimônio Cultural, RS, 2011.

RAMALHO, R. R. Reescrever ou inventar uma história? Associação Psicanalítica de Porto Alegre, Porto Alegre, n. 30, p.25-34, jun. 2006. Semestral. Disponível em:<http://www.appoa.com.br/uploads/arquivos/revistas/revista30-1.pdf>

RICKES, S. M.; GLEICH, P. Letras em oficina: a afirmação retumbante do "não". Psicologia Social, Florianópolis, v. 21, 2009. Disponível em: <http:/ /www.scielo.br/ scielo.php?script=sci_arttext\&pid=S0102-71822009000400017\&lng=en\&nrm=iso $>$.

RIVERA, T. Arte e Psicanálise. Rio de Janeiro: Jorge Zahar Editor, 2002. p.75.

VORCARO, A. O efeito bumerangue da classificação psicopatológica da infância. In: JERUSALINSKY, Alfredo; FENDRIK, Silvia (Org.). O livro negro da psicopatologia contemporânea. 1. ed. São Paulo: Via Lettera, 2011. p.219-230. 